Proc. Indian Acad. Sci. (Earth Planet. Sci.), Vol. 101, No. 3, September 1992, pp. 201-213.

(C) Printed in India.

\title{
Spatial variability of aridity over northern India
}

\author{
NITYANAND SINGH, G B PANT and S S MULYE \\ Indian Institute of Tropical Meteorology, Dr. Homi Bhabha Marg, Pashan, Pune 411008 ,
} India

MS received 1 October 1991; revised 25 May 1992

\begin{abstract}
Spatial variability of aridity over northern India (north of $20^{\circ} \mathrm{N}$ ) is studied by examining variations in the arid area. Area with an objectively determined summer monsoon rainfall (June to September total) of less than $500 \mathrm{~mm}$ is identified as arid area. The summer monsoon rainfall of 212 rain-gauges from 212 districts of the region for the period 1871-1984 are used in the analysis. An interesting feature of the arid area series is that it shows decreasing trend from beginning of the present century. The summer monsoon rainfall fluctuations over five subjectively divided zones over northern India are examined to understand the association between rainfall and the arid area variations. The rainfall series for northwest India shows a significant inereasing trend and that for northeast India a significant decreasing trend from the beginning of this century. Rainfall fluctuations over the remaining zones can be considered intermediate stages of a systematic spatial change in the rainfall pattern. This suggested that the recent decreasing trend in the arid area is due to a westward shift in the monsoon rainfall activities. From correlation analyses it is inferred that perhaps the recent decreasing trend in the arid area and increasing trend in the monsoon rainfall over northwest India are associated with a warming trend of the northern hemisphere.
\end{abstract}

Keywords. Aridity; arid area and rainfall fluctuations; summer monsoon circulation; northern hemisphere surface air temperature.

\section{Introduction}

Understanding climatic variability of the arid area of Northwest India, the Indian counterpart of the Thar desert, otherwise known as Rajasthan or Rajputana desert or the Great Indian desert, has been a problem of special interest. The importance of the area is that it is a part of the land mass which once (B.C. 2300 to $1750 \pm 100$ ) hosted the people of the great Indus Valley, or Harappan culture. The Indus Valley culture is considered as the largest of the three most ancient civilizations of the world (Wheeler 1953).

The various climate variability studies for the Northwest India can be broadly grouped into two categories. Firstly, the long-term (on the time scales of centuries and millenia) variability studies which were carried out using a variety of proxy data, and were mostly intended to determine the climatic (rainfall) conditions during the period of the Indus Valley civilization. Results of most of these studies are given in a review article by Pant and Maliekal (1987). From the available evidences, they have identified four broadly demarcated epochs namely, before $10000 \mathrm{yr}$ B.P. (cold-dry); 10000 to 4500 yr B.P. (warm-humid with frequent floods); 4500 to 3500 yr B.P. (warm-humid equable climate with less extremes) and 3500 yr B.P. to present (warm-dry frequent droughts with seasonal extremes) in the climatic history of the region during the Holocene period. It is now accepted that compared to the present day, wetter climatic conditions 
prevailed over the area, and decline of the culture occurred in association with a drastic decrease of rainfall (Singh et al 1974).

Secondly, the short-term variability studies which were carried out using about a century-long instrumental data (see Parthasarathy and Dhar 1978). Winstanley (1973) showed a declining trend in the monsoon rainfall and southward shift in the isohyets and the desert boundary at approximately $1 \mathrm{~km} /$ year over the 36-yr period from 1926 to 1961 over Sahara and Rajasthan. He had also predicted, by extrapolating a longterm rainfall trend, that 'around the year 2030, the isohyets and the desert climate will be some 150 to $180 \mathrm{~km}$ further south than in 1930'. By the other investigators have found rainfall fluctuations over northwest India homogeneous and random in time domain. Contrary to Winstanley, in a recent study Pant and Hingane (1988) found an increasing trend in the annual and summer monsoon rainfall in and around Rajasthan desert.

Rajasthan is the most thickly populated desert of the world and a majority of the people are dependent on agriculture for their livelihood and therefore the desertification is a problem of serious concern. Desertification is highly dependent upon the loss of vegetation cover. Knowledge of the temporal variability of rainfall has been found to be of limited help to know the changes in the vegetation cover and desertification. Using satellite derived data on vigour and quantity of vegetation cover, numerous studies have demonstrated that there existed a close association between spatial variability of rainfall and the vegetation cover (Nicholson et al 1991 and references therein). To understand the variations of the vegetation cover in dry regions of India, Singh et al (1992) studied the spatial variations of the arid area during the period 1871-1984 and demonstrated that the arid area series (1871-1984) displayed declining tendency during the last 45 years. The three main objectives of the present study are : (i) To examine the spatial variations of the arid area during the summer monsoon season over northern India (north of $20^{\circ} \mathrm{N}$ ), (ii) To understand association between the arid area and the summer monsoon rainfall variations over northern India, and (iii) To investigate impact of the warming trend of the northern hemisphere on the arid area and rainfall variations over northern India.

\section{Data used}

\subsection{The summer monsoon rainfall}

The summer monsoon rainfall (June to September total) data of a long period 18711984 (114 yrs) from a network of 212 rain-gauges well spread over the subtropical (north of $20^{\circ} \mathrm{N}$ ) Indian region (figure 1) are used in the study. The 212 rain-gauges are located in 212 districts (a small administrative unit) of the study area. Details about this data set are given by Mooley and Parthasarathy (1984). This processed data set was obtained from Dr. B Parthasarathy. Mountainous areas in the north which lie outside the conventional limits of the Asian summer monsoon regime are not considered in the study. These are shaded by horizontal lines in figure 1 . Thus, the study area is situated under the descending branch of the tropical Hadley circulation.

2.1a Arid area series: Singh (1984) demonstrated that Thornthwaite's type of climatic classification of India can be done using the mean annual rainfall alone. The arid zones 


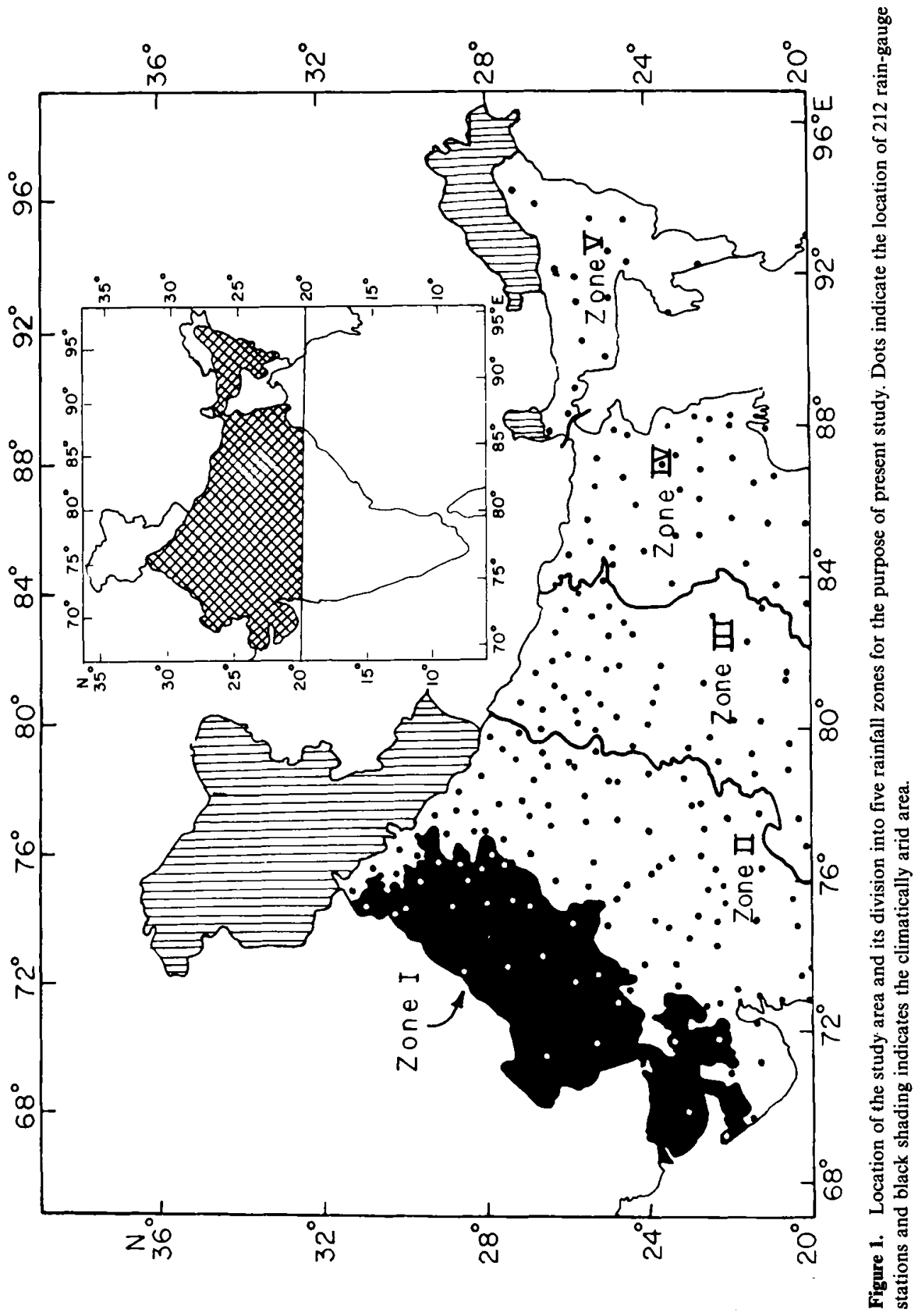




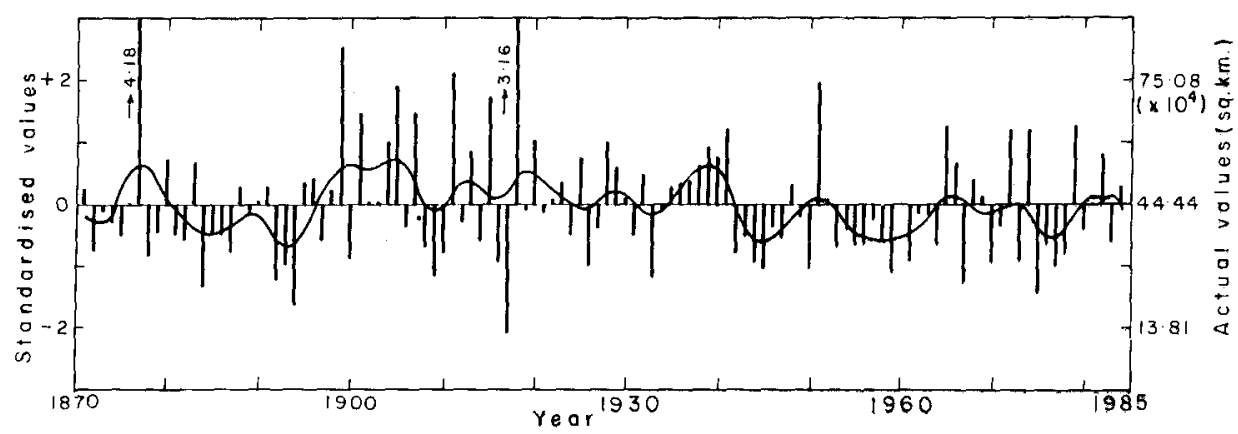

Figure 2. The year-to-year variation of the arid area during the period 1871-1984. The smoothed values are obtained by applying a 9-point gaussian low pass filter with truncated end points.

were identified as the areas with the mean annual rainfall less than $561 \mathrm{~mm}$. Summer monsoon rainfall contributes about $90 \%$ to the annual total over major parts of northern India. Therefore arid zones can be identified as areas with mean summer monsoon rainfall less than $500 \mathrm{~mm}$ (figure 1). This was found to agree with the arid zones of India classified by Subrahmanyam (1956) using the rational approach of Thornthwaite. To study the fluctuations of the arid area, an arid area series for the period 1871-1984 was prepared by getting the yearwise total area of the districts which received summer monsoon rainfall less than $500 \mathrm{~mm}$. This was done by assuming that the station rainfall amount would represent rainfall over a district in which the station is located. On a standardized scale (actual minus mean divided by standard deviation) the arid area series is presented in figure 2.

2.1b Summer monsoon rainfall series for different parts of the northern India: To determine the association between the arid area and the summer monsoon rainfall variations over northern India, the summer monsoon rainfall variations over different parts of the area were studied. The area was divided into five zones and summer monsoon rainfall series was prepared. The climatically arid zone in the west/northwest and the humid regions of northeast India were considered as two zones at the two ends of the study area. The main difference between the two areas is that over the northwest India rainfall was the lowest and over the northeast it was the highest. The rainfall fluctuations over the two subregions were negatively correlated (Subbaramayya 1968). Further, the zone in the extreme west is a region with large-scale subsidence and drier conditions whereas the zone in the extreme east is an area of large scale moist convection due to monsoon currents and orography. To study the rainfall fluctuations in some detail, the remaining parts of the study area were divided into three equal (breadthwise) zones as the area is a region of transition between two climatic zones with different characteristics of the rainfall fluctuations. The five zones delineated for the purpose of the present study are shown in figure 1 . The number of stations falling in each zone is given in the bottom row of table 1. A summer monsoon rainfall series for each of the five zones was prepared by averaging district-area weighted rainfall amount at stations in the particular zone (figure 3 ). 
Table 1. Statistical properties of the arid area and the five summer monsoon rainfall series of northern India (1871-1984).

\begin{tabular}{|c|c|c|c|c|c|c|}
\hline \multirow{2}{*}{$\begin{array}{l}\text { Statistical } \\
\text { parameter }\end{array}$} & \multirow[b]{2}{*}{ Arid area } & \multicolumn{5}{|c|}{ Summer monsoon rainfall } \\
\hline & & Zone-I & Zone-II & Zone-III & Zone-IV & Zone-V \\
\hline Mean & $444431 \mathrm{~km}^{2}$ & $329 \cdot 4 \mathrm{~mm}$ & $769.0 \mathrm{~mm}$ & $1011.3 \mathrm{~mm}$ & $1071 \cdot 1 \mathrm{~mm}$ & $1681.1 \mathrm{~mm}$ \\
\hline Standard deviation & $153844 \mathrm{~km}^{2}$ & $107.6 \mathrm{~mm}$ & $146.9 \mathrm{~mm}$ & $156.9 \mathrm{~mm}$ & $127.5 \mathrm{~mm}$ & $167 \cdot 3 \mathrm{~mm}$ \\
\hline Coeff. of variation & $34.6 \%$ & $32.6 \%$ & $19 \cdot 1 \%$ & $15.5 \%$ & $11 \cdot 6 \%$ & $9.9 \%$ \\
\hline Median & $418755 \mathrm{~km}^{2}$ & $315.5 \mathrm{~mm}$ & $785.6 \mathrm{~mm}$ & $1010.8 \mathrm{~mm}$ & $1095 \cdot 1 \mathrm{~mm}$ & $1680.5 \mathrm{~mm}$ \\
\hline $\mathbf{g}_{1}$ (skewness) & $1 \cdot 18$ & 0.10 & -0.66 & -0.31 & $0 \cdot 16$ & 0.21 \\
\hline $\mathbf{g}_{2}$ (kurtosis) & $2 \cdot 32$ & -0.04 & 0.31 & 0.14 & -0.48 & 0.24 \\
\hline $\mathbf{g}_{1} / \mathbf{S E}\left(\mathbf{g}_{1}\right)$ & $5 \cdot 21$ & 0.46 & -2.91 & $-1 \cdot 39$ & 0.73 & 0.91 \\
\hline $\mathbf{g}_{2} / \mathrm{SE}\left(\mathbf{g}_{2}\right)$ & $5 \cdot 16$ & -0.10 & 0.70 & 0.32 & -1.06 & 0.54 \\
\hline Lowest value & $120614 \mathrm{~km}^{2}$ & $90.7 \mathrm{~mm}$ & $318.6 \mathrm{~mm}$ & $569 \cdot 2 \mathrm{~mm}$ & $824.0 \mathrm{~mm}$ & $1300.8 \mathrm{~mm}$ \\
\hline Year of occurrence & 1917 & 1899 & 1877 & 1877 & 1966 & 1896 \\
\hline Highest value & $1084745 \mathrm{~km}^{2}$ & $621.3 \mathrm{~mm}$ & $1061.6 \mathrm{~mm}$ & $1351 \cdot 3 \mathrm{~mm}$ & $1407 \cdot 2 \mathrm{~mm}$ & $2176.2 \mathrm{~mm}$ \\
\hline Year of occurrence & 1877 & 1917 & 1961 & 1980 & 1922 & 1878 \\
\hline t-statistic & -0.89 & 0.47 & $1 \cdot 35$ & -0.50 & -1.06 & -1.68 \\
\hline$(-)$ & $-2 \cdot 40^{*}$ & $1 \cdot 80$ & $2.94^{*}$ & 0.03 & $-2 \cdot 08^{*}$ & $-2 \cdot 12^{*}$ \\
\hline$\tau$-statistic & -0.03 & 0.01 & 0.02 & -0.36 & -0.05 & -0.11 \\
\hline$(-)$ & $-0.15^{*}$ & $0 \cdot 15^{*}$ & $0.23^{* *}$ & -0.03 & -0.11 & $0 \cdot 19^{*}$ \\
\hline $\begin{array}{l}\text { No. of runs about } \\
\text { the median }\end{array}$ & 56 & 64 & 59 & 53 & 60 & 57 \\
\hline No. of stations & - & 25 & 85 & 48 & 37 & 17 \\
\hline
\end{tabular}

(-) Test result based on data of the period 1901-1984.

* Significant at $5 \%$ level and above.

**Significant at $1 \%$ level and above.

\subsection{Surface air temperature of the northern hemisphere.}

Monthly surface air temperature anomalies of the northern hemisphere for the period 1901-1984 (Jones et al 1986) were also used to study the association between the variations in the surface air temperature of the northern hemisphere and the variations in the arid area and the monsoon rainfall over northern India. Representativeness of the available northern hemisphere temperature data prior to 1901 was limited and was therefore not used in the correlation analysis.

\section{Analysis of the arid area series}

\subsection{Statistical properties of the arid area series}

A set of statistical parameters describing chief properties of the arid area series (18711984) are given in table 1 . With a mean of $444431 \mathrm{~km}^{2}$ the relative interannual variability (C.V.) of the arid area is $34.6 \%$, which is large. During years of extreme summer monsoon rainfall activities, the area under arid conditions can vary from a small value of $120614 \mathrm{~km}^{2}(1917)$ to a large value of $1084745 \mathrm{~km}^{2}(1877)$.

The nature of spatial variations (expansion and contraction) of the arid area is illustrated by presenting arid area during four years for each of extremely small, near- 


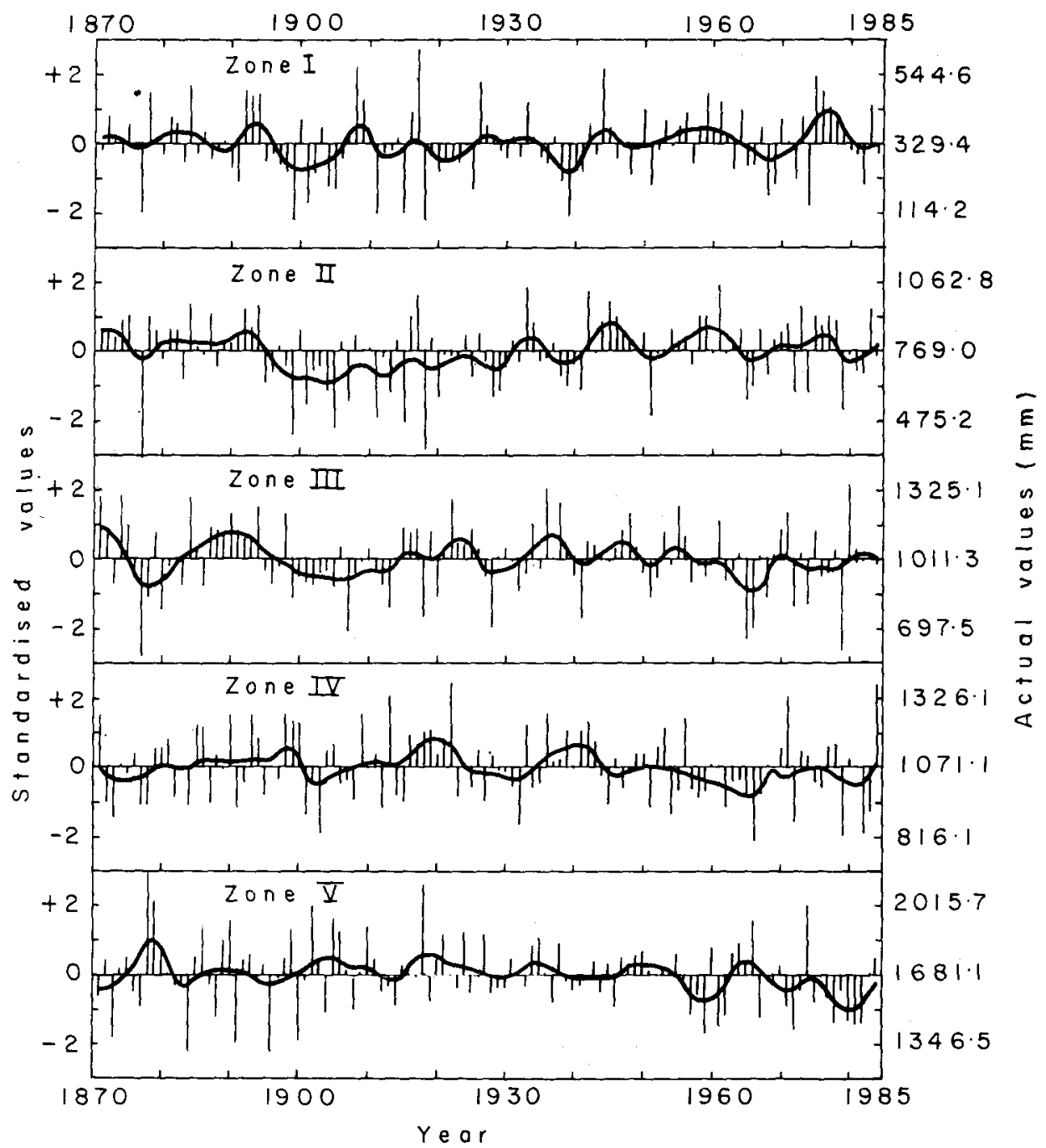

Figure 3. Actual and 9-point smoothed summer monsoon rainfall series for the five rainfall zones of northern India.

normal and extremely large cases in figure 4. The years have been identified after arranging the arid area series in an ascending/descending order. During its nearnormal size the arid area resembles a climatically arid zone (figure 1). In certain extreme years, only few districts in the western border of the country experience arid conditions while in other extreme years it spreads well beyond its normal limits towards east and south along the gentle slope of the isohyets. Because of a rigid criterion of 'summer monsoon rainfall less than $500 \mathrm{~mm}$ ' isolated districts under arid conditions can be seen. Nevertheless it can be grossly inferred that the arid area of northern India expands and contracts in a somewhat organized manner.

To understand the nature of the frequency distribution of the arid area series it has been tested for the normal distribution by applying Fisher's g-test (Rao 1952). The test requires computation of the coefficients of skewness $\left(\mathrm{g}_{1}\right)$ and kurtosis $\left(\mathrm{g}_{2}\right)$ and tests 


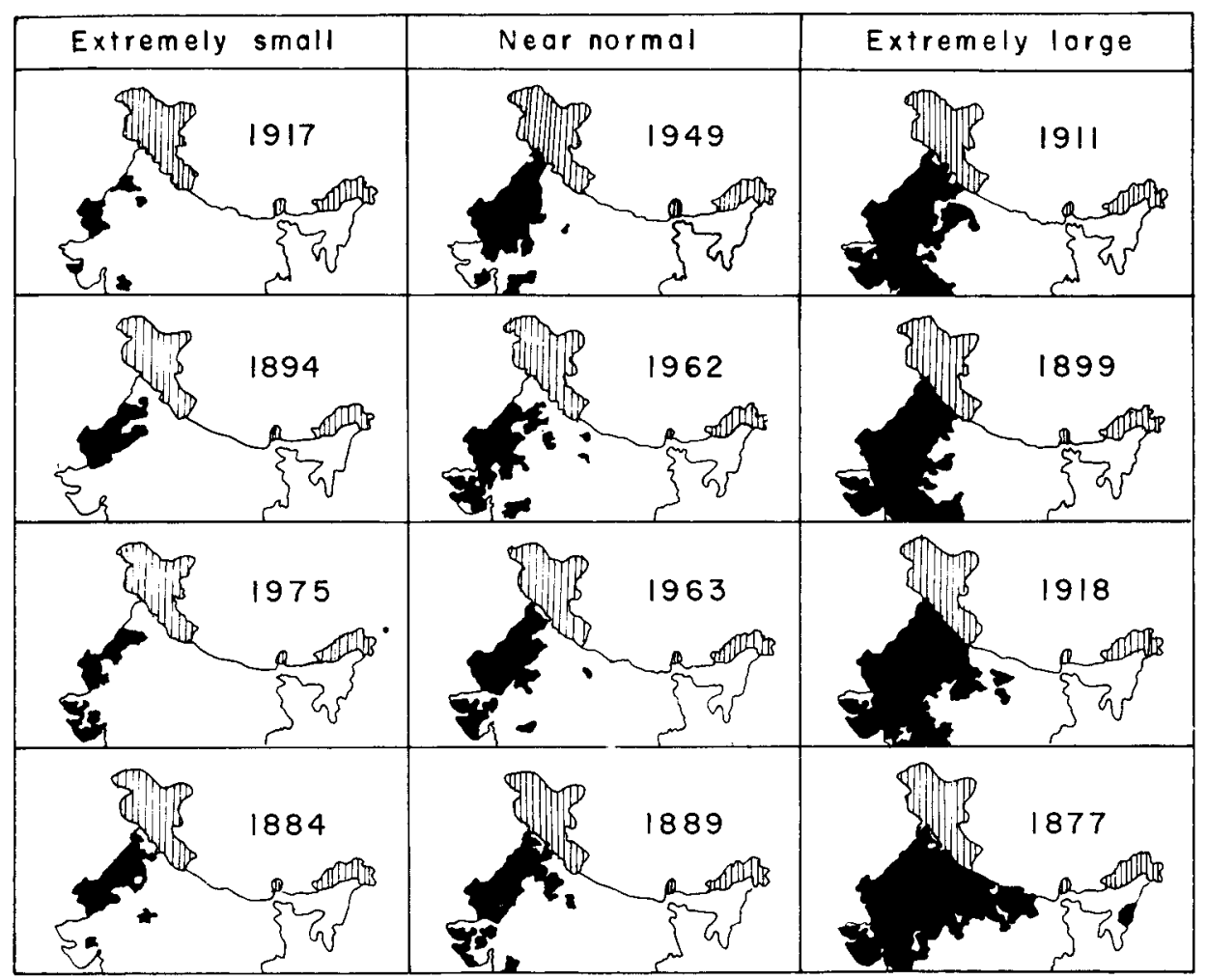

Figure 4. Area under arid conditions for four years in each of the three categories viz., extremely small, near-normal and extremely large.

statistic $g_{1} / S E\left(g_{1}\right)$ and $g_{2} / S E\left(g_{2}\right)$ (where $S E$ denotes standard error). If either of $\mathrm{g}_{1} / \mathrm{SE}\left(\mathrm{g}_{1}\right), \mathrm{g}_{2} / \mathrm{SE}\left(\mathrm{g}_{2}\right)$ or both are greater than $|2.00|$ the distribution of the series under investigation is treated as significantly different (at $5 \%$ level) from normal. For the arid area series the different parameters of the g-test are given in table 1. The test suggests that the arid area series is significantly different from normal distribution. But the square-root transformation of the arid area series is found to be near-normal according to the Fisher's g-test.

\subsection{Fluctuation characteristics of the arid area series}

3.2a Long term features: Relative interannual variability of the arid area is large. In order to examine fluctuations in a low frequency mode the arid area series was smoothed by a 9-point Gaussian low-pass filter (WMO 1966) with truncated end points (figure 2). From smoothed series three broad epochs can be identified in the arid area fluctuations: 1880-1896 (wet epoch), 1897-1941 (dry epoch) and 1942-1980 (wet epoch). This is broadly consistent with the periods of the all-India summer monsoon rainfall fluctuations (Mooley and Parthasarathy 1984). The all-India rainfall series is highly correlated with the rainfall series of northwest India.

To examine whether arid area variations have undergone any significant long-term 
change, three chosen statistical tests namely Student's t-test on the difference between means of the two subperiods of equal length, Mann-Kendall Rank test of randomness against trend ( $\tau$-test) and Swed-Eisenhart Runs (above and below the median) test (WMO 1966) have been applied. The tests statistic are given in table 1. The different tests suggest an insignificant decreasing trend in the arid area series. Since distribution of the arid area series is not normal, these tests have been applied on its square-root values. Results of trend analysis similar to the actual data were also obtained in this case.

According to $\tau$ and $t$-tests the decreasing trend in the arid area series for the period $1901-1984$ is statistically significant at $5 \%$ level (table 1 ).

3.2b Short term features: Episodic type fluctuations have been seen in a filtered version of the arid area series. To examine the significance of the deviation of persistently large/small values of the arid area from its long term mean the Cramer's $t_{k}$ test (WMO

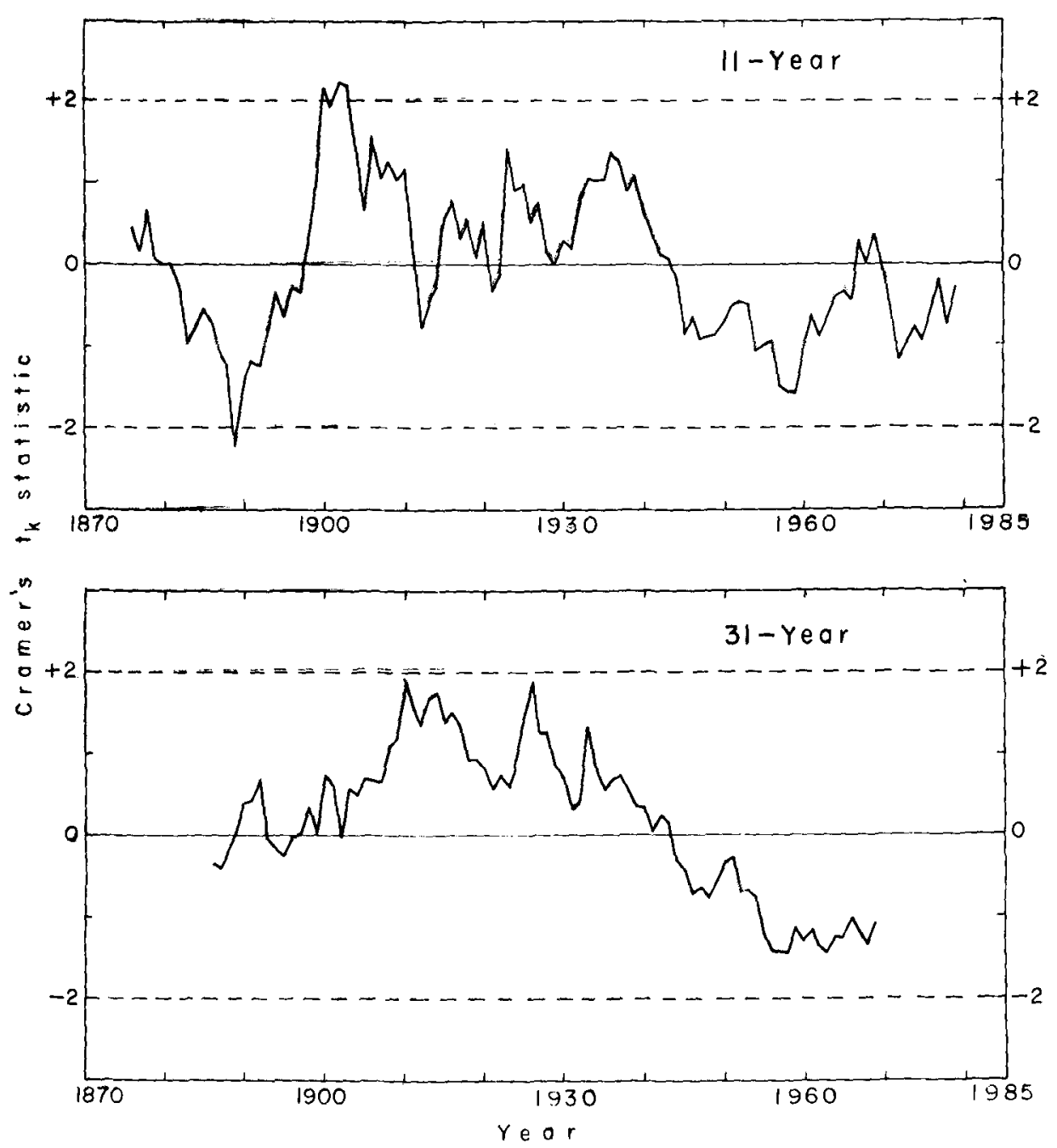

Figure 5. Cramer's $t_{k}$-statistic applied on 11 and $31-y r$ running means of the arid area series. 
1966) has been applied. The $t_{k}$ statistic for the 11 and 31-year running means of the arid area series is presented in figure 5. The 11-yr means first declined and attained the lowest value significantly (at $5 \%$ level) below the overall mean centered around the year 1889. They increased sharply and attained the highest value significantly (at $5 \%$ level) above the overall mean around 1902. Thereafter fluctuations were within normal limits with values above the overall mean upto 1942 and below afterwards.

The 31-yr running means showed a rising trend in the beginning and attained a peak

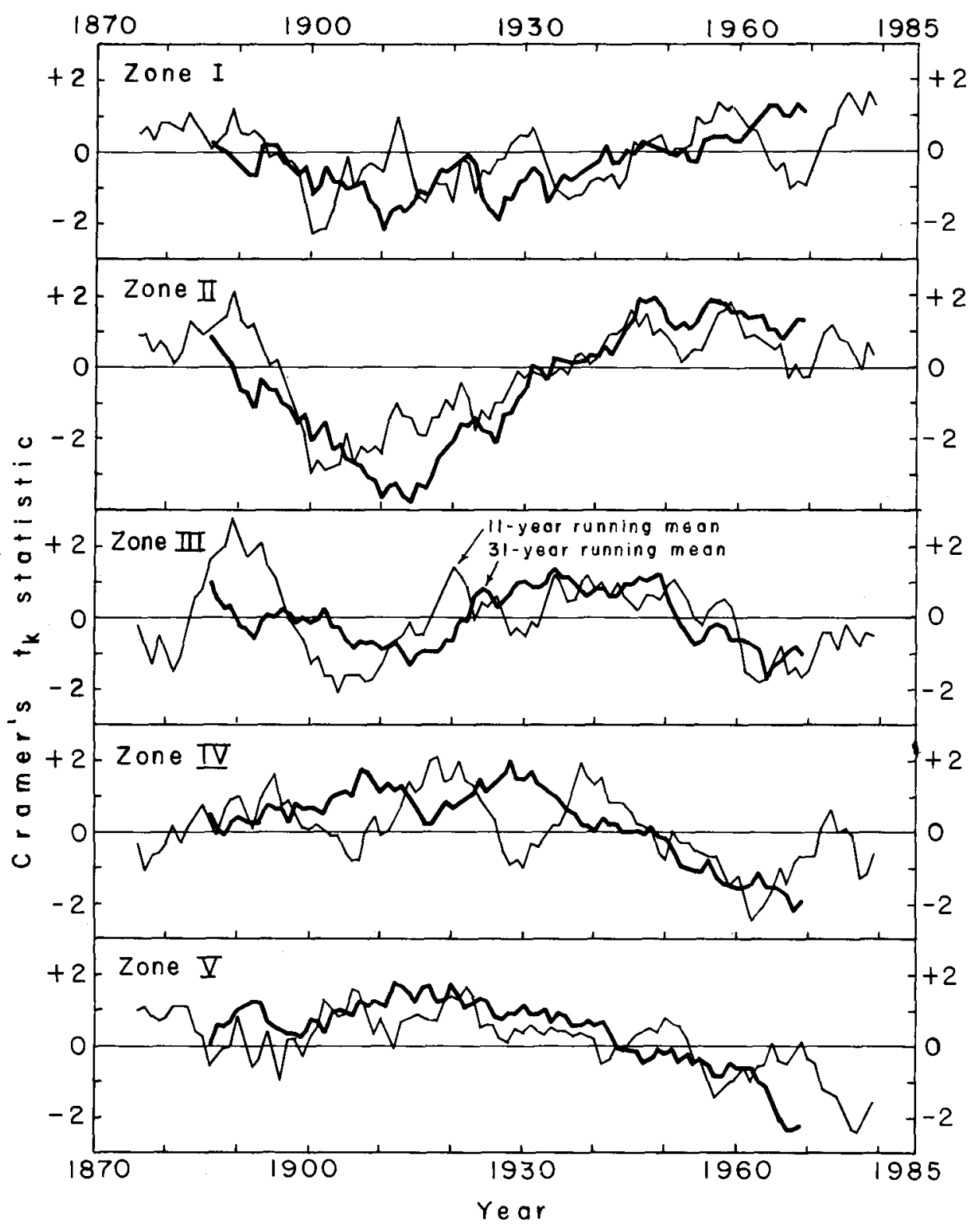

Figure 6. Cramer's $t_{k}$-statistic applied on 11 and 31-yr running means of the summer monsoon rainfall series for five zones. 
during 1895-1925. After declining for sometime they increased sharply and attained another peak during 1911-1941. But thereafter they showed a declining trend.

\section{Characteristics of the summer monsoon rainfall series for the five zones}

\subsection{Statistical properties}

The important statistical parameters for the summer monsoon rainfall series of the five zones are given in table 1. The mean rainfall increases and the coefficient of variation decreases from west to east. This is consistent with the well known rainfall characteristics of the region.

The parameters of the $\mathrm{g}$ test applied for testing normality aspects are given in table 1 for all the five summer monsoon rainfall series. The different rainfall series are normal, except for Zone II which suffers from negative kurtosis.

\subsection{Fluctuation characteristics}

The smoothed rainfall series by a 9-point Gaussian low-pass filter for the five zones have displayed aperiodic episodic type fluctuations. Application of $t$ test on the difference between means of the two equal subperiods, Mann-Kendall Rank test $\tau$ and Swed-Eisenhart Run test did not suggest a significant long term trend in any of the rainfall series. The Cramer's $t_{k}$-statistic for the 11 and 31-yr running means of the summer monsoon rainfall series is presented in figure 6. The 11-yr running means for the different zones have displayed aperiodic oscillatory characteristics. But 31-yr running means showed increasing trend for the Zone I and Zone II and decreasing trend for the Zone IV and Zone V from the beginning of the present century. For the period 1901-1984 the increasing trend in the rainfall for Zone I ( $\tau$ test ) and Zone II ( $t$ and $\tau$ tests) and decreasing trend for Zone IV ( $t$ test) and Zone $V$ ( $t$ and $\tau$ tests) are statistically significant at $5 \%$ level and above. From this change in the rainfall spatial pattern and significant (at 5\% level) decreasing trend in the arid area during 1901-1984 (table 1) it was inferred that in the recent $40-45$ years there was a westward shift in heavy rainfall activities over northern India.

\section{Association between the arid area and the rainfall fluctuations over northern India and the northern hemisphere surface air temperature}

Through variations in location and strength the mid-tropospheric circumpolar westerlies of the northern hemisphere influence the monsoons of the northern summer (Winstanley 1973; Lamb 1974). Surface air temperature is a good indicator of the state of the westerlies. During warmer northern hemisphere strong westerlies with relatively long, small amplitude waves are restricted to mid-latitudes. During cooler northern hemisphere weak westerlies with relatively short, large amplitude waves tend to shift southwards into subtropical, or even tropical, latitudes. When the strong westerlies are shifted to mid-latitudes the monsoon currents penetrate farther northward and give heavier rains. The opposite situation prevails when weak westerlies are shifted southwards (Winstanley 1973). A general warming occurred throughout the northern hemisphere (Jones et al 1986; Hansen and Lebedeff 1987). It was speculated that the 
Table 2. Correlation coefficient (CC) for 5-yr running mean of the arid area series and the five summer monsoon rainfall series with 5-yr running of the April-June temperature of the northern hemisphere based on data of the period 1901-1984.

\begin{tabular}{lcc}
\hline & $\begin{array}{c}\text { Corr. Coeff. } \\
\text { Parameter }\end{array}$ & $\begin{array}{c}\text { No. of effective } \\
\text { degrees of freedom } \\
\left(N_{\text {eff }}\right)\end{array}$ \\
\hline Arid area & $-0.40^{*}$ & 32 \\
Zone-I rainfall & 0.14 & 32 \\
Zone-II rainfall & $0.58^{* *}$ & 31 \\
Zone-III rainfall & $0.34^{*}$ & 32 \\
Zone-IV rainfall & -0.04 & 32 \\
Zone-V rainfall & $-0.46^{* *}$ & 31 \\
\hline
\end{tabular}

* Significant at 5\% level ** Significant at 1\% level.

strength of the circumpolar westerlies was increased. Correlations were studied between the arid area and the five rainfall series of northern India and the monthly, bimonthly, trimonthly etc and annual surface air temperature of the northern hemisphere based on data of the period 1901-1984. The correlation coefficients (CCs) for the 5-yr running means of the arid area and the five monsoon rainfall and the AprilJune temperature of the northern hemisphere are given in table 2. The statistical significance of the linear $\mathrm{CC}$ is tested against effective degrees of freedom $\left(\mathrm{N}_{\text {eff }}\right)$ which is calculated as follows (Quenouille 1952)

$$
N_{\text {eff }}=N /\left(1+2 r_{1} r_{1}^{\prime}\right)
$$

where $N$ is the number of observations (here it is 84), and $r_{1}$ and $r_{1}^{\prime}$ are the first lag autocorrelation coefficient for the two series under analysis. $N_{\text {eff }}$ is given in table 2 .

Positive correlation $(\mathrm{CC})$ of the northern hemisphere temperature with the rainfall series for Zone II is significant at $1 \%$ level and negative correlation with the rainfall series for Zone $\mathrm{V}$ is significant at $5 \%$ level. As the temperature of the northern hemisphere increases the rainfall over the northwest India increases and that over the northeast India decreases. Quoting the work of Ramaswamy (1965) Subbaramayya (1968) provided an explanation for the opposite behaviour of the rainfall variations over northwest and northeast India. During the high index circulation (strong westerlies) over Siberia the Tibetan high is well developed, elongated and extends much to the west, the monsoon trough is located to the south of its usual position, and westward/northwestward moving monsoon depressions from the Bay of Bengal give heavier rains over the whole country, particularly over the western parts. During low index circulation of the mid-latitude westerlies the embedded large amplitude troughs cause temporary partial destruction of the Tibetan high or the Tibetan high is poorly developed over east/southeast of its usual position. This situation besides being favourable for break monsoon condition giving very little or no rain over major parts of the country, would direct the depressions to move northwards and the rainfall is mainly concentrated over northeast India.

Correlation coefficient between the northern hemisphere temperature and rainfall of 
Zone $I$ is not significant. Perhaps during the situations of further warmer northern hemisphere and westward shift of the rainfall activities the correlation may tend to be significant. Around 2000 B.C. the summer temperatures in Europe were $2-3^{\circ} \mathrm{C}$ higher than the present one (Dragan and Airinei 1987). High latitude temperature is a good indicator of thermal conditions of the entire hemisphere. Due to large northerly penetration of the monsoon currents and heavy rainfall activities the Indus culture flourished in the northwest India during this period. There are ample reliable evidences of westward shift in the rainfall activities at certain times in the past 10000 yrs of climatic history of Rajasthan (Singh et al 1974). Hence, spatial fluctuation in rainfall on different time scales was a dominant component of the climatic fluctuations over northwest India.

\section{Conclusions}

The arid area of the northern India with a mean of $444431 \mathrm{~km}^{2}$ exhibits large interannual variations of $34.6 \%$. An interesting feature of the arid area series is that it shows a significant decreasing tendency from the beginning of the present century.

From the rainfall fluctuations over different parts of northern India it is inferred that decrease in the arid area is due to a westward shift in the rainfall activities.

During warmer northern hemisphere northwest India gets relatively higher rainfall and northeast India relatively lower rainfall. A rising trend of the northern hemisphere surface air temperature may be identified as a possible cause of an increasing trend in the monsoon rainfall and a decreasing trend in the arid area over northwest India. But the underlying physical mechanism appears to operate on a climatological scale rather than on year-to-year basis.

\section{Acknowledgements}

Authors are grateful to the Director, Indian Institute of Tropical Meteorology, Pune for necessary facilities; to the India Meteorological Department for the basic rainfall data; to Dr. S V Singh, B Parthasarathy and D K Paul for fruitful discussions and to the two anonymous referees for constructive comments.

\section{References}

Dragan J C and Airinei S 1987 Geoclimate and history (Roma-Italia: Editrice, Nagard, Foro Traiano) pp 354 Hansen $J$ and Lebedeff S 1987 Global trends of measured surface air temperature; $J$ Geophys. Res. 92 13345-13372

Jones P D, Raper S C B, Diaz H F, Kelly P M and Wigley T M L 1986 Northern hemisphere surface air temperature variations: 1851-1984; J. Climat Appl. Meteorol. 25 161-179

Lamb H H 1974 The current trend of world climate: A report on the early 1970's and a perspective; Climatic Research Unit, Report No. 3, Norwich, England, pp. 25

Mooley D A and Parthasarathy B 1984 Fluctuations in all-India summer monsoon rainfall during 1871-1978; Climatic Change 6 287-301

Nicholson S R, Davenport M L and Malo A R 1991 A comparison of the vegetation response to rainfall in the Sahel and East Africa using normalized difference vegetation index from NOAA AVHRR; Climatic Change 17 209-241 
Pant G B and Hingane L S 1988 Climatic change in and around the Rajasthan desert during the 20th century; J. Climatol. 8 391-401

Pant G B and Maliekal J A 1987 Holocene climatic changes over Northwest India: An appraisal; Climatic Change 10 183-194

Parthasarathy B and Dhar O N 1978 Climatic fluctuations over Indian region-rainfall: A review; Research Report RR-025, Indian Institute of Tropical Meteorology, Pune, India pp. 37

Quenouille M H 1952 Associated measurements (London: Butterworths) pp. 242

Ramaswamy C 1965 On the synoptic methods of forecasting the vagaries of southwest monsoon over India and neighbouring countries; The symposium on meteorological results of the Indian Ocean Expedition, 22-26 July 1965, Bombay, India, 317-336

Rao C R 1952 Advanced statistical methods in biometric research (New York: John Wiley and Sons) p. 210

Singh G, Joshi R D, Chopra S K and Singh A B 1974 Late quaternary history of vegetation and climate of Rajasthan, India; Philos. Trans. R. Soc. London Ser B267 467-501

Singh N 1984 Fluctuations of different moisture regimes in India; Arch. Meteorol., Geophys. Bioklimatol., Ser. B35 239-256

Singh N, Mulye S S and Pant G B 1992 Some features of the arid area variations over India: 1871-1984; Pure Appl. Geophys. 138 135-150

Subbaramayya I 1968 The inter-relations of monsoon rainfall in different sub-divisions of India; J. Meterol. Soc. Jpn. $4677-84$

Subrahmanyam V P 1956 Climatic types of India according to the rational classification of Thornthwaite; Indian J. Meteorol. Geophys. 7 253-264

Wheeler Sir Mortimer 1953 The Cambridge history of India. The Indus Civilization (London: Cambridge University Press)

Winstanley D 1973 Rainfall patterns and general atmospheric circulation; Nature (London) 245 190-194

World Meteorological Organization 1966 Climatic Change; WMO Technical Note No. 79 WMO No. 195-TP-100, Geneva, pp. 79 